\title{
The Exploration on the Course System Construction of the Physical Education and Training Graduate
}

\author{
Li'e Wang $^{1, \text { a }}$, Fenshan Liu ${ }^{2, b}$ \\ ${ }^{1,2}$ YuLin, University, Shaanxi Province, YuLin, 719000. \\ hunter2011@foxmail.com
}

Keywords: Physical Education and Training, Course System Construction, Exploration

\begin{abstract}
This paper uses literature, visit investigation, logical analysis and other research methods to analysis the current course system construction of physical education and training postgraduates. By analyzing the characteristics and problems of course system of our current physical education and training graduate, we proposed the basic elements and the principled framework which should be considered to build the curriculum system of physical education and training postgraduates
\end{abstract}

\section{Introduction}

In 1997 by the Academic Degrees Committee of the State Council promulgated a master's degree and graduate training in the discipline, specialty catalog, will be classified as sports science disciplines, the Physical Education and Training (subjects) Professional zoned two disciplines. Correct Understanding of Physical Education and Training disciplines (professional) orientation and comply with the requirements of the times, strengthen the sports system construction postgraduate education training school, it has become a major concern of the degree granting unit. With the development of scientific and technological progress, improve people's quality of life, people pay more attention to health, to deepen understanding of the sport, leading to increased demand for sports talent, performance sports colleges to expand graduate enrollment, the size of graduate education has been super conventional development. One of the main purposes of education is to train graduate students the ability to undertake scientific research or independent take on a special technical work. So, whether it is an independent research activities, or organized teaching activities must pay attention to develop learner research capacity. At the same time, education is also a graduate professional education, and science and technology is the social division of labor is reflected in the highly differentiated field of higher education. As to graduate courses, only to strengthen their professional construction can they meet the needs of all sectors of society for high-level professionals [1].

\section{The Existing Main Problems of the Course System of Physical Education and Training Graduate}

All along, we do so with a degree in two disciplines set point, and this curriculum, training graduate students. Meanwhile, China's postgraduate education is also prevalent because people set up courses and course name change does not change the case of the course content. This curriculum model can not adapt to the current needs of sports development [2].

There are too many single subject courses and few comprehensive courses. Currently schools are based on two subjects (Physical Education and Training) degree set point, and thus set the course graduate students, this arrangement has led to graduate too specialized knowledge structure and knowledge necessary to narrow the ability to adapt relatively narrow, affecting the formation of students' good knowledge structure.

There are too much duplicate contents, research and cutting-edge is not enough. Over the years, we have set on Physical Education and Training professional courses, part of the curriculum does not reflect some of the latest knowledge and research disciplines, especially in the hot field of professional discipline, focus and remaining controversial issues, course content more obsolete, 
reducing the enthusiasm of students to explore new knowledge.

The number of elective courses is too few and the setting of interdisciplinary and elective course has not attracts enough importance. Universities offer elective door number varies widely, fewer elective school gates opened and the student lack of choice is not conducive to the cultivation of students' personality. Interdisciplinary elective provisions were made, some universities are not even out of the interdisciplinary elective course, is not conducive to expand student knowledge, build a reasonable knowledge structure.

Research methods curriculum has not got inadequate attention. Graduate students are the future scientists, their research training received normal time and it will directly affect their future career achievements and ability to engage in scientific research. Institutions of higher education in the United States research method is widely used as a first step to academic training, and as one of the best students in the methods of scientific research. Graduate Education of Physical Education in the process of training, lack of knowledge of scientific research methods training is one of the main reasons leading to postgraduate research and innovation ability is generally low. How in a targeted manner to strengthen education and training of scientific research methods to improve their research capacity, became the key to improving the quality of Physical Education and Training Graduate Studies. In addition, Tsinghua University, Beijing University of Physical Education, Shanxi Normal University, three research methods will be classified as professional basic courses and professional courses, the school has over the course of the research methods are classified as elective courses. And we set up in the curriculum of other subjects in scientific research methods Survey found that sports humanistic sociology, human movement science, education and other professional attach great importance to scientific research methods course open, and the inclusion of compulsory courses [3].

\section{The Basic Elements of Curriculum System Construction of Physical Education and Training Graduate}

The subject connotation. With the development of modern sports science and interdisciplinary penetration, Physical Education and Training and the traditional disciplines are increasingly pedagogy, psychology, physical education, biology and other disciplines integration. Curriculum Physical Education and Training, and must accurately reflect the professional discipline connotation, and in the professional and related disciplines and two subjects closely.

The cultivation patterns. Currently, the Higher Education worldwide, mainly divided into the following categories: 1) general education model, emphasizing students basic skills, such as the ability to solve problems, the ability of independent learning, communication and teamwork ability, etc; 2 ) practical professional model, emphasizing the students' learning and social production practices closely, so that students can graduate competent job of work; 3) counterparts professional education model, a clear division of professional boundaries, emphasizing the professional range of in-depth study. With the rapid development of modern science and technology and social trends generate diversified demand for graduate students, the traditional model of professional counterparts seem increasingly unsuited to the development of society. Currently, the curriculum reform of professional education model proposed wide caliber, emphasizing expertise teaching contents and curricular system a solid foundation of knowledge, wide caliber, knowledge of flexible jobs in curriculum system design, it is necessary to highlight the traditional sports learn the basics of education and training, but also take into account the cross-penetration of Physical Education and Training and other sports disciplines.

The cultured target. In a sense, the training objectives of graduate education to the curriculum as an intermediary can be achieved, in practice, it is also the curriculum as a basic means and ways to achieve the goal of postgraduate education and training. Thus, graduate education and training objectives and content of education graduate courses selection, curriculum and system construction has a direct relationship. Degree and postgraduate education in the beginning of recovery, China's higher education and science and technology undone, urgent need to establish a teaching and research team, which determines the country's graduate education start with the obvious characteristics of 
academic research. Especially sports disciplines postgraduate training less because the initial enrollment, employment face a single, resulting in a postgraduate training has been used a single training objectives and training model. Too much emphasis on theoretical depth, theoretical projections postgraduate education training objectives to be achieved in the course of mediation, in practice, it is also the curriculum as a basic means and ways to achieve the goal of postgraduate education and training. Thus, graduate education and training objectives and content of education graduate courses selection, curriculum and system construction has a direct relationship. Degree and postgraduate education in the beginning of recovery, China's higher education and science and technology undone, urgent need to establish a teaching and research team, which determines the country's graduate education start with the obvious characteristics of academic research. Especially sports disciplines postgraduate training less because the initial enrollment, employment face a single, resulting in a postgraduate training has been used a single training objectives and training model. We have put too much emphasis on theoretical depth, theoretical breakthrough, ignoring the graduate creative ability, practical ability and entrepreneurial spirit.

In addition to current society requires a certain amount of academic high-level talents, but requires a lot of energy to solve practical problems, multi-skill applied, compound talents. Physical Education and Training Physical discipline belong to the technical disciplines should emphasize training objectives and training model diversification, more should pay attention to the curriculum system construction in the application of knowledge to learn, to meet the needs of modern society for this specialty.

The features of college. In the survey, we found that because of differences in cultural background and competent school system, geography, etc., resulting in these institutions even in the same discipline also tend to have different research and teaching focus, so in the curriculum system settings, these college wide caliber professional aspect emphasized, on the other hand, is trying to highlight the characteristics of their own institutions, thus forming a professional curriculum with different institutions in different specialties. This requires that the design of the curriculum system should not only reflect the principle, but also have the flexibility to reflect the characteristics of the university postgraduate training, to make the curriculum with a distinct personality [4].

\section{The Principled Framework of Courses System Construction of Physical Education and Training Graduate}

According to the principles of the disciplines curriculum. Press disciplines to develop training programs, according to a discipline platform course is the development trend of Physical Education and Training Graduate Students. Physical Education and Training Discipline training objectives requires students to have a broad subject knowledge, innovative skills and good cooperation and conduct interdisciplinary research with people, which is a requirement for quality of postgraduate training new situation presented, but also the purpose of graduate education. To this end, the Course System to reflect scientific rationality, emphasis on knowledge of the discipline structure covering the various professions. To provide students with education and training in the field of sports basic theoretical knowledge necessary in-depth study and research institutes. Platform as a framework it should be able and Physical Education and Training in the four disciplines related to the curriculum as a pillar. These courses cover various professional direction, it is the foundation engaged in professional research.

Cutting-edge and comprehensive principles. Physical Education and Training have the discipline not only basic theory and system expertise, but also have the relevant knowledge frontier. Curriculum first refers to new cutting-edge issues and trends in the field of research and development of professional academic research focus, difficulty focusing and remaining controversial; secondly curriculum must highlight the research program, exploratory; third, cutting-edge also it includes the latest developments and trends in cross-cutting edge and cross-disciplinary research in the field. Setting these courses is to enable students to master the basic theoretical knowledge and basic skills relevant disciplines Physical Education and Training in the desired direction of research, which 
includes courses and seminars in the direction of the course.

Personalized principle. The goal of graduate education point to their culture, although the requirements of graduate students with a sense of cooperation and character studies, and promote cooperation in postgraduate academic temperament, but graduate education is not to train students for the purport of common, not all-round development the man with a model for the development. In this sense, personalization is the main goal of postgraduate education and training constituted. This requires that the curriculum should be flexible, based on a different basis and graduate research knowledge, curriculum has a flexible, increasing the number of gates elective courses, elective graduate left a large room, so that students can be personalized highlights [5].

Quality principle. In constructing curriculum system, we should focus on basic knowledge, professional theory, sports skills training curriculum balanced mix, focusing on the combination of knowledge and skills to improve student competency-based, change "counterparts concept" to "adapt the concept of" change "professional counterparts education" to "enhance the adaptability of education", with the focus of scientific research methods, sports practice and other capabilities in order to improve the quality of graduate students. Based on the above principles, physical education training disciplines (specialty) Postgraduate Course System, in addition to public classes, should offer five levels of courses: internet courses, orientation courses, elective courses, academic research programs, comprehensive curricula.

\section{Conclusion}

The construction of curriculum system of physical education and training graduate should focus on cutting-edge curriculum and multidisciplinary, focusing on knowledge structure and ability structure, highlighting the personalized curriculum, which is the basic principle of constructing a reasonable physical education and training graduate curriculum system and it is also an important guarantee to cultivate high quality, high-level innovative talents.

\section{References}

[1] M. L. Pan. Talking about the necessity and feasibility of adaptation the master course evaluation system, Guangdong Technology University, 2003 (3).

[2] W.P. Ma, Research on Oriented PE education specialized curriculum system in the 21st century, Beijing Sports University, 2000 (3).

[3] Z.Q. Deng. The research on reform and development of physical education and training, Beijing Sports University, 2010 (3).

[4] A.B. Xie. The construction of reasonable course system of PE graduate education, Higher Education Research, 2003, 5 (24).

[5] X.S. Gu, The exploration of setting postgraduate courses according to press disciplines, China Higher Education Research, 2004, 8. 